\title{
A case of spastic paraplegia type 11 with a variation in the SPG11 gene
}

\author{
Muhsin Elmas ${ }^{1^{*}}$ D, Basak Gogus ${ }^{1}$, Banu Değirmenci², Mustafa Solak ${ }^{1}$ and J. G. Gleeson ${ }^{3,4}$
}

\begin{abstract}
Background: Spastic paraplegia 11 (SPG11) is defined as progressive spasticity and weakness of the lower limbs and also associated with mild intellectual disability with learning difficulties in childhood and/or progressive cognitive retardation, peripheral neuropathy, pseudobulbar symptoms, and increased reflexes in the upper limbs. We describe the clinical, laboratory, and radiological presentation of SPG11 through a report of a case and compare with previously reported SPG11 cases in the literature.

Case presentation: This case presents a homozygous variant in the SPG11 gene (NM_025137.4): C.1699C>T; p. $\left(G \ln 567^{*}\right)$.

Conclusion: The diagnosis was made based on molecular findings, thinning of corpus callosum (TCC) and in most cases, periventricular white matter abnormalities are detected in brain MRI. Therefore, the clinical and radiological findings are supporting the diagnosis. However, it should not be forgotten that TCC is not peculiar to SPG11.
\end{abstract}

Keywords: Spastic Paraplegia, Hereditary, Corpus callosum dysgenesis, Intellectual disability

\section{Background}

Hereditary spastic paraplegia (HSP) is a group of neurodegenerative diseases that are clinically and genetically heterogeneous and is characterized with spasticity of the lower limbs [1]. The genetic inheritance pattern of disease have a broad range like autosomal recessive (AR), autosomal dominant $(\mathrm{AD})$, and $\mathrm{X}$-linked recessive (XLR) inheritance. More than 70 different loci have been identified in the etiology of HSP (SPG1-71) [2].

Clinically, HSPs are divided into two groups as pure and complex form. Pure HSP forms are presented with progressive spasticity in lower extremities, increased deep tendon reflexes and extensor plantar reflex without any additional neurological deficits. Complex HSP forms are manifested with additional neurological and nonneurological symptoms such as seizures, ataxia, dementia, peripheral neuropathy, optic atrophy, cognitive retardation, deafness and retinopathy, or cataract [3].

\footnotetext{
* Correspondence: drmelmas@gmail.com

${ }^{1}$ Medical Genetics Department, Afyonkarahisar Health Sciences University, Afyonkarahisar, Turkey

Full list of author information is available at the end of the article
}

The age of onset for the disease is quite variable and both early and late onset can be seen. Thinning of corpus callosum (TCC) is a hallmark for a subset of complex HSP forms. One of the HSP subgroups that is associated with TCC is "autosomal recessive inherited HSP (ARHSP) SPG11" (Online Mendelian Inheritance in Man [OMIM] \#604360) [4]. Patients with SPG11 are presented with early onset progressive spastic paraparesis, intellectual disability, peripheral neuropathy, thin corpus callosum, and periventricular white matter abnormalities [5]. In addition, these patients may have urinary incontinence, sensory deficits in lower limbs, distal amyotrophy, seldom seizures, extrapyramidal signs, and cerebellar ataxia [6].

We describe the clinical, laboratory, and radiological presentation of SPG11 through a report of a case and compare with previously reported SPG11 cases in the literature.

\section{Case presentation}

The case is a 13-year-old male patient whose parents have consanguineous marriage (first cousins), born in 
Afyonkarahisar. He presented with walking disability, moderate learning disability, impairment of muscular strength in the extremities, bilateral trigger fingers in the fifth fingers, spasticity of lower limbs, hyperactive deep tendon reflex, and pes cavus (Fig. 1).

Prenatal, natal, and postnatal history of the patient were coherent. The motor development stages of the patient were concordant with his age. All developmental stages of the patient (motor, social and language) were normal before eight years of age. After eight years of age, the patient's intellectual ability and academic performance began to impair. He was unable to lift his feet off the ground while walking when he was about 9 years old. Therefore, he began to walk by dragging his feet and also started to fall while walking. Then, bilateral trigger finger in the fifth fingers developed. He was unable to fully extend his both little fingers. In addition, nocturnal enuresis started by the age of 10 (Fig. 1). (The parents consented the publication of clinical findings and photographs.)

Then, the patient's pedigree was drawn. First cousin marriage was present between the parents. No similar cases were found in the family.

Physical examination revealed impairement of muscle strength in four extremities. Also, spasticity was found in the feet. The deep tendon reflexes were hyperactive. Bilateral pes cavus was also observed in the feet. The patient had dysarthria. Bilateral contraction was observed in the fifth fingers (Fig. 1). He had mild dysmorphic features including hypertelorism, horizontal eyebrows, downslanted palpebral fissures, telecanthus, prominent antitragus, expanded terminal portion of crus helix, macrotia, broad columella, low insertion of columella, enlarged nares, wide nasal bridge, broad nasal tip, thin upper lip vermillon, and diastema at anterior incisor teeth. In the neurological examination of the patient, deep tendon reflexes were found to be hyperactive in the lower extremities. The clinical findings of the patient are summarized in Table 1.

Brain magnetic resonance imaging (MRI) of the patient revealed periventricular hyperintensity and diffuse thin corpus callosum (Fig. 2). Electromyographic examination did not show any pathological abnormalities. Echocardiography was normal.

Detection of spasticity in the lower extremities, deterioration in walking, pes cavus, and speech disorder provided a prediagnosis of hereditary spastic paraplegia. However, due to diversity of this disease group, a definitive diagnosis would only be possible with genetic testing. The existence of consanguinity between parents made us to perform whole exome sequencing (WES). In the WES analysis, a homozygous variant was detected in the SPG11 gene (NM_025137.3): c.1699C >T;p. $\left(G \ln 567^{*}\right)$. Analysis of the patient's parents showed that they were

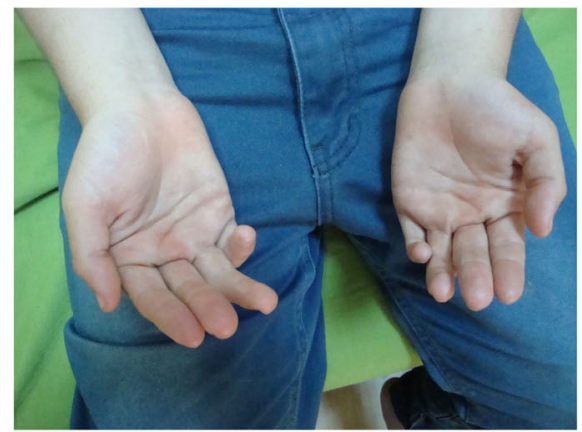

A

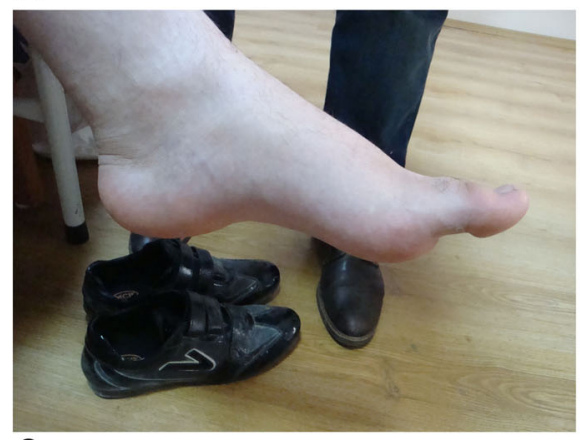

C

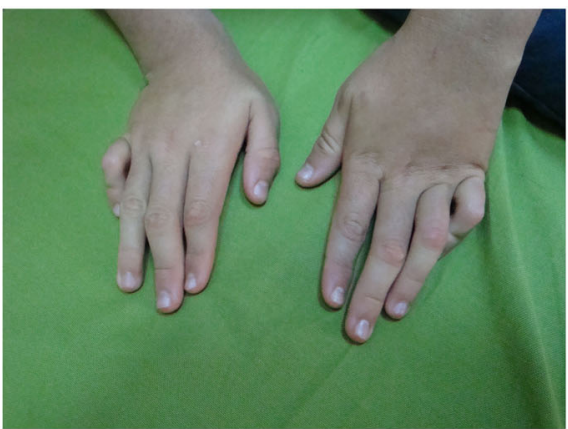

B

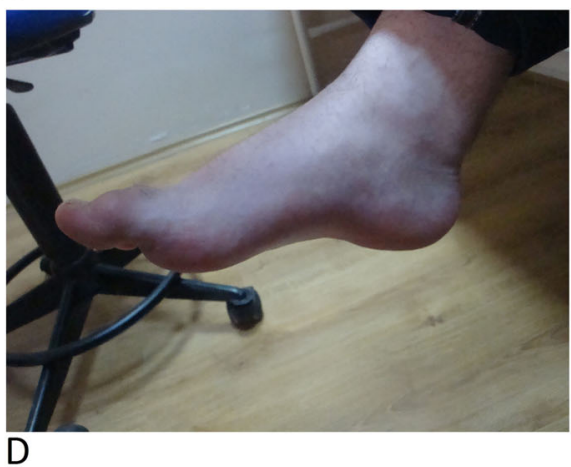

13-year old patient's pictures. Images A-B are showing trigger fingers. Images C-D are showing pes cavus.

Fig. 1 Clinical findings of the patient 
Table 1 Clinical findings of SPG 11 and comparison with our case

\begin{tabular}{ll}
\hline Frequent findings & Our case \\
\hline Mild intellectual disability with learning difficulties in childhood and/or progressive cognitive retardation (83\%) & + \\
Axonal, motor, or sensorimotor peripheral neuropathy $(>80 \%)$ & - \\
Pseudobulbar involvement with dysarthria and/or dysphagia (85\%) & + \\
Hyperactive reflexes in the upper limbs (> 80\%) & + \\
Less frequent findings & - \\
Cerebellar signs (ataxia or ocular signs including nystagmus and/or saccadic pursuit) & $?$ \\
Retinal degeneration (Kjelling syndrome) & + \\
Pes cavus & - \\
Scoliosis & - \\
Extrapyramidal signs such as parkinsonism & - \\
\hline
\end{tabular}

heterozygous for the same variant. This variant is classified as "pathogenic" according to American College of Medical Genetics and Genomics classification. The Deleterious Annotation Of Genetic Variants Using Neural Networks (DANN) score of this mutation is 0.9959 , and it is "disease causing" in MutationTaster. Owing to the detection of this variant, we made the patient's definitive diagnosis as "spastic paraplegia 11, autosomal recessive." This variant was also confirmed by Sanger sequence analysis method.

\section{Discussion}

In this case study, the clinical features of a patient with a variant in the SPG11 gene were identified. There are approximately 50 cases defined for this disease according to our literature research. Based on these cases, the clinical findings were identified in GeneReviews database [7]. These findings and the information about their presence in our case are shown in Table 1.

In the Karim et al. study, the clinical findings of a patient with a variant in the SPG11 gene were described.

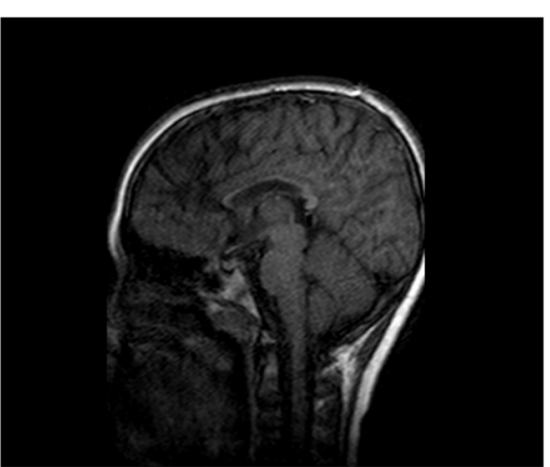

A

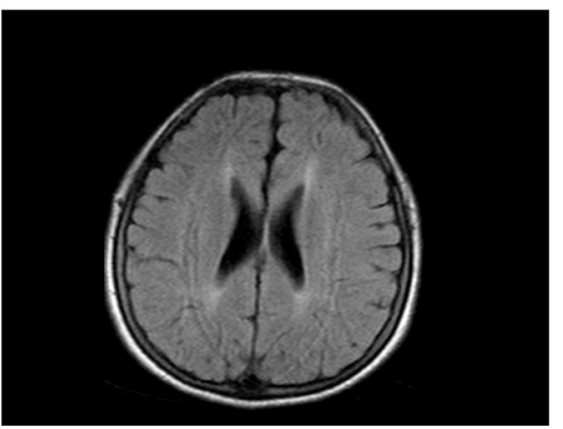

C

Brain MR images A-B are showing thin corpus callosum and cerebellar hypoplasia, C-D are showing periventricular leukomalacia

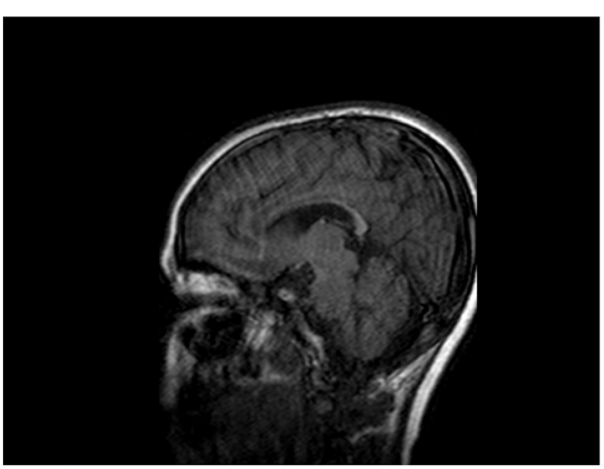

B

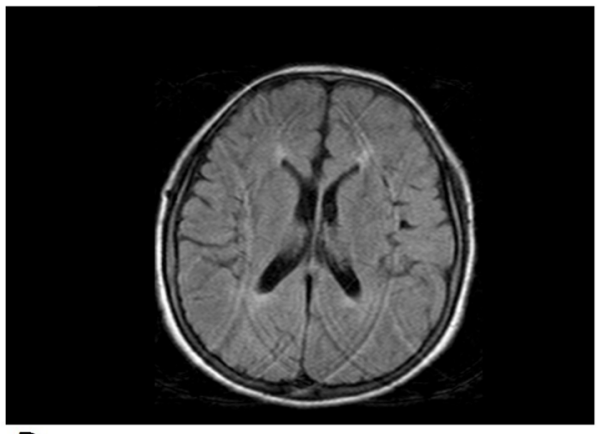

D

Fig. 2 Brain MRI findings of the patient 
In this case, hyperextension was described in the fingers of the patient [8]. In the Wijemanne et al. study, the HSP case with a SPG11 gene variant had limited extension and flexion at fingers [9]. Even in the same subgroup of the disease, it is possible to have different phenotypes. In our case, we found limited extension in the fifth finger.

Hyperintense areas in brain MRI have been previously presented in SPG11 patients. However, this is not considered to be a specific finding of SPG11 [10]. At the same time, the thin corpus callosum detected in our case is an expected finding in SPG11 patients and has been reported in literature $[11,12]$.

In the literature of SPG11 patients, we found a similar situation for urinary incontinence in the case report of Winner et al., that they reported two German sisters with SPG11 [13]. However, the patient had a combined axonal loss and demyelinating sensory neuropathy that was not in our patient. Although our patient had pes cavus, a sign of neuropathy, the EMG result of the patient was normal.

Casali et al. reported 18 patients from 12 Italian families with HSP-TCC. Two of the families were consanguineous. The clinical phenotype was homogeneous: gait difficulties beginning at a median age of 13 (with a range of 4 to 20) and progressing impairement of ambulation for approximately 10 years. The age of onset was 8 years and impairement of ambulation appeared at 10 years of age in our patient [14].

As a summary, SPG11 presented with different clinical symptoms. Currently, neurodegenerative diseases began to diagnose easily with the advancement of genetic testing techniques. However, each mutation occurring in one gene may cause different clinical symptoms.

\section{Conclusion}

We determined the diagnosis based on molecular findings, thinning of corpus callosum (TCC), and in most cases, periventricular white matter abnormalities are detected in brain MRI. Therefore, the clinical and radiological findings supported our diagnosis. However, it should be considered that TCC is not a specific finding for SPG11. Patients should be evaluated with a comprehensive anamnesis, detailed clinical, laboratory, and imaging techniques because the better the clinical evaluation is, the more easily the mutation can be revealed.

\section{Supplementary information}

Supplementary information accompanies this paper at https://doi.org/10. 1186/s43042-020-00072-6.

Additional file 1:. CARE Checklist of information to include when writing a case report

\section{Abbreviations}

SPG11: Spastic paraplegia 11; TCC: Thinning of the corpus callosum; HSP: Hereditary spastic paraplegia; AR: Autosomal recessive; AD: Autosomal dominant; XLR: X-linked recessive; OMIM: Online Mendelian Inheritance in Man; WES: Whole exome sequencing

\section{Acknowledgements}

Not applicable.

\section{Authors' contributions}

M.E conceived and designed the study. B.G and B.D performed clinical assessments. M.S and J.G performed the experiments, and contributed to data acquisition, analysis and interpretation. B.G drafted the manuscript. All authors contributed to critical revision of the manuscript for intellectual content and final approval of the manuscript. All authors have read and approved the manuscript.

\section{Funding}

No funding was received for this research project.

\section{Availability of data and materials}

Data can be found in the archives of the Afyon Health Sciences University Hospital.

Ethics approval and consent to participate

Not applicable.

\section{Consent for publication}

Written informed consent was obtained from the parents of the patient.

\section{Competing interests}

The authors declare that they have no competing interests.

\section{Author details}

${ }^{1}$ Medical Genetics Department, Afyonkarahisar Health Sciences University, Afyonkarahisar, Turkey. ${ }^{2}$ Medical Genetic Department, Hatay Public Hospital, Hatay, Turkey. ${ }^{3}$ Department of Neurosciences, Howard Hughes Medical Institute, University of California, San Diego, La Jolla, CA 92093, USA. ${ }^{4}$ Rady Children's Institute for Genomic Medicine, San Diego, CA 92025, USA.

Received: 17 December 2019 Accepted: 11 June 2020

Published online: 15 July 2020

References

1. Stevanin G, Azzedine ÃH, Denora ÃP, Boukhris ÃA, Tazir M, Lossos A, et al. Mutations in SPG1 1 are frequent in autosomal recessive spastic paraplegia with thin corpus callosum, cognitive decline and lower motor neuron degeneration. 2008:

2. Chrestian N, Dupré N, Gan-Or Z, Szuto A, Chen S, Venkitachalam A et al (2016) Clinical and genetic study of hereditary spastic paraplegia in Canada. Neurol. Genet. 3

3. Uyanik G, Özgül RK, Gross C, Cirak S, Elibol B, Anlar B, et al. Further Clinical and Genetic Characterization of SPG11 : Hereditary Spastic Paraplegia with Thin Corpus Callosum. 2006;59-66.

4. Paisan-ruiz C, Nath P, Wood NW, Singleton A, Houlden H. Clinical heterogeneity and genotype-phenotype correlations in hereditary spastic paraplegia because of Spatacsin mutations ( SPG11 ). 2008;1065-70.

5. Pensato V, Castellotti B, Gellera C, Pareyson D, Ciano C, Nanetti L et al (2014) Overlapping phenotypes in complex spastic paraplegias SPG11, SPG15, SPG35 and SPG48. Brain 137:1907-1920

6. Lossos A, Stevanin G, Meiner V, Argov Z, Bouslam N, Newman JP et al (2006) Hereditary spastic paraplegia with thin corpus callosum: reduction of the SPG11 interval and evidence for further genetic heterogeneity. Arch. Neurol. 63:756-760

7. Spastic Paraplegia 11 - GeneReviews ${ }^{\oplus}$ - NCBI Bookshelf.

8. Nikkhah K, Ghabeli Juibary A, Sadr-Nabavi A. A Novel c.4822>T Mutation on SPG11 in an Iranian Patient Marked by Hereditary Spastic Paraparesis and Skeletal Deformity: An Incidental Finding or a True Association. 2016.

9. Wijemanne S, Shulman JM, Jimenez-shahed J, Curry D, Jankovic J. SPG11 Mutations Associated With a Complex Phenotype Resembling DopaResponsive Dystonia. 2015;149-54. 
10. Laurencin C, Rascle L, Cotton F, Grosset-Janin C, Bernard E, Depienne C et al (2016) A rare case of SPG11 mutation with multiple sclerosis. Rev. Neurol. (Paris). 172:389-391

11. Örlén $H$, Melberg A, Raininko R, Kumlien E, Entesarian M, Söderberg P et al (2009) SPG11 mutations cause Kjellin syndrome, a hereditary spastic paraplegia with thin corpus callosum and central retinal degeneration. Am. J. Med. Genet. Part B Neuropsychiatr. Genet. 150:984-992

12. Guidubaldi A, Piano C, Santorelli FM, Silvestri G, Petracca M, Tessa A et al (2011) Novel mutations in SPG11 cause hereditary spastic paraplegia associated with early-onset levodopa-responsive Parkinsonism. Mov. Disord. 26:553-556

13. Winner B, Uyanik G, Gross C, Lange M, Schulte-Mattler W, Schuierer G, et al. Clinical Progression and Genetic Analysis in Hereditary Spastic Paraplegia With Thin Corpus Callosum in Spastic Gait Gene 11 (SPG11). Arch. Neurol. [Internet] 2004 [cited 2018 Nov 29];61:117. Available from: http://archneur. jamanetwork.com/article.aspx?doi=10.1001/archneur.61.1.117

14. Casali C, Valente EM, Bertini E, Montagna G, Criscuolo C, De Michele G, et al. Clinical and genetic studies in hereditary spastic paraplegia with thin corpus callosum. Neurology [Internet] 2004;62:262 LP - 262268. Available from: http://n.neurology.org/content/62/2/262.abstract

\section{Publisher's Note}

Springer Nature remains neutral with regard to jurisdictional claims in published maps and institutional affiliations.

\section{Submit your manuscript to a SpringerOpen ${ }^{\odot}$ journal and benefit from:}

- Convenient online submission

- Rigorous peer review

- Open access: articles freely available online

High visibility within the field

- Retaining the copyright to your article

Submit your next manuscript at $\boldsymbol{\nabla}$ springeropen.com 